\title{
Ovarian Hemangioma Presenting with Ascites and Elevated CA125
}

Safa A. Ameer Hasan AI-Shaikh*

Salmanyia Medical Complex, Bahrain

*Corresponding author: Safa A. Ameer Hasan Al-Shaikh, Salmanyia Medical Complex, Bahrain, Tel: 9-73 1728 8888; E-mail: dr_salshaikh@hotmail.com; SShaikh1@health.gov.bh

Received date: April 20, 2016; Accepted date: April 29, 2016; Published date: May 05, 2016

Copyright: ( 2016 Al-Shaikh SAAH. This is an open-access article distributed under the terms of the Creative Commons Attribution License, which permits unrestricted use, distribution, and reproduction in any medium, provided the original author and source are credited.

\begin{abstract}
Ovarian hemangiomas are rare tumors. We report a case of ovarian hemangioma with unusual presentation. Here, we report a 60 year female presented with massive ascites and high CA125. Abdominopelvic computed tomography $(\mathrm{CT})$ showed a right adnexal mass $8 \times 7 \mathrm{~cm}$. The radiological impression was of a right ovarian tumor. Microscopically, benign vascular lesion composed of small capillary sized vessels.
\end{abstract}

\section{Introduction}

Ovarian hemangiomas are extremely rare tumors. Most are cavernous type and are asymptomatic [1]. So far, less than 60 cases have been reported in the literature. In all age groups, ranging from infancy to elderly [2-6]. Here, we report a case of ovarian cavernous hemangioma presented with ascites and high CA125.

\section{Case Report}

A 60-year-old woman, known case of hypertension and diabetes, presented with two months history of progressive shortness of breath and abdominal pain and distension without any improvement with diuretics. Computed Topography scan of her abdomen and pelvis contrast showed significant ascites in upper and lower abdomen, and showed a right adnexal mass measuring $8 \times 7 \mathrm{~cm}$ with a $3 \times 4$ cyst and soft tissue component which is well-defined, having an irregular outline and heterogeneously intensely enhancing (Figure 1).

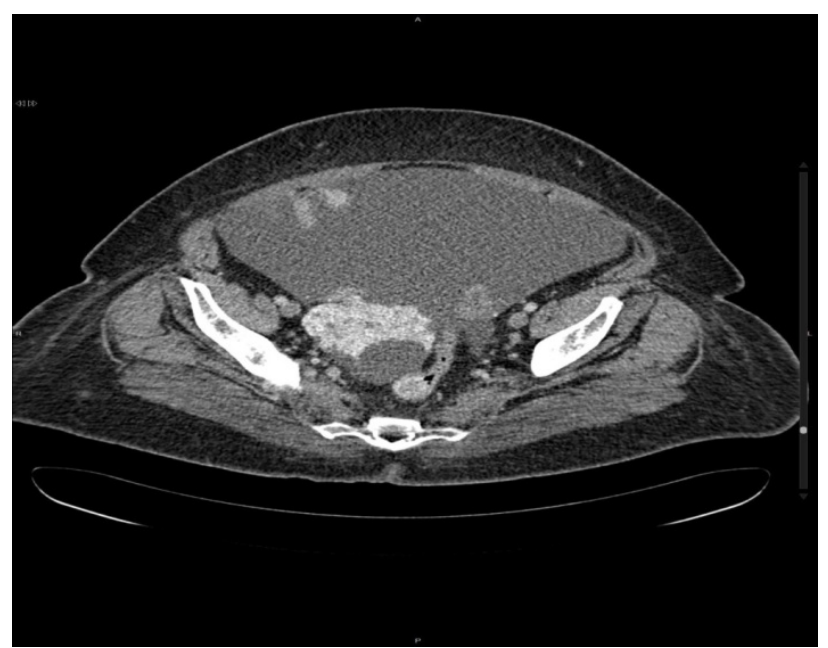

Figure 1: Abdominopelvic computed tomography showing a right adnexal mass $8 \times 7 \mathrm{~cm}$.
The right ovarian vein was also dilated. No significant lymph nodes or omental thickening was noted. Both uterus and left ovary were unremarkable. Blood investigations showed significantly elevated CA-125 levels (2032 u/ml, Normal 0-35 u/ml). Cytologic examination of ascitic fluid was negative for malignant cells.

The patient underwent total abdominal hysterectomy and bilateral salpingoophorectomy, omentum and left pelvic lymph node dissection. The uterus showed only atrophic endometrium. Left ovary and both fallopian tubes were unremarkable. The lymph node was reactive. The omentum was negative for malignancy. The right ovary measured $6.2 \times$ $5.7 \times 3 \mathrm{~cm}$ and weighed 54 grams. The outer capsule was intact and smooth. Serial sectioning showed multiple cysts filled with hemorrhagic material along with grey brown solid areas.

The histopathologic examination of the right ovary revealed benign vascular tumor consistent with ovarian hemangioma (Figure 2).

\section{Discussion}

Hemangiomas are generally uncommon benign vascular tumors in the gynecological tract. They are extremely rare in the ovary, despite its rich and complex vascularity. Ovarian hemangiomas were reported in all age groups, ranging from infancy to elderly [1-6]. The first case report of ovarian hemangiomas was by Payne et al. in 1869. It was a case of bilateral ovarian hemangiomas co-existing with abdominopelvic hemangiomatosis in a 25 year old female $[7,8]$.

The etiology of hemangiomas in general is controversial. In the ovary, it is still not known if they are true neoplasms, hamartomas, or congenital malformations. However, their formation may be stimulated by some factors, such as hormones mainly estrogen, pregnancy, or infection [6]. The International Society for the Study of Vascular Anomalies has recommended that only lesions that arise as a result of cellular proliferation can be called hemangiomas, on the presumption that they are true neoplasms. Typically they are composed of capillary vessels growing in a disproportionately rapid fashion relative to the patient. Whereas, vascular malformations, in contrast, are developmental abnormalities of the embryonic vasculature. They develop in utero, present at birth, grow proportionately with the patient, and display little proliferative activity. They are composed of any combination of arteries, veins, and capillaries. Some are associated with specific genetic defects [9]. 


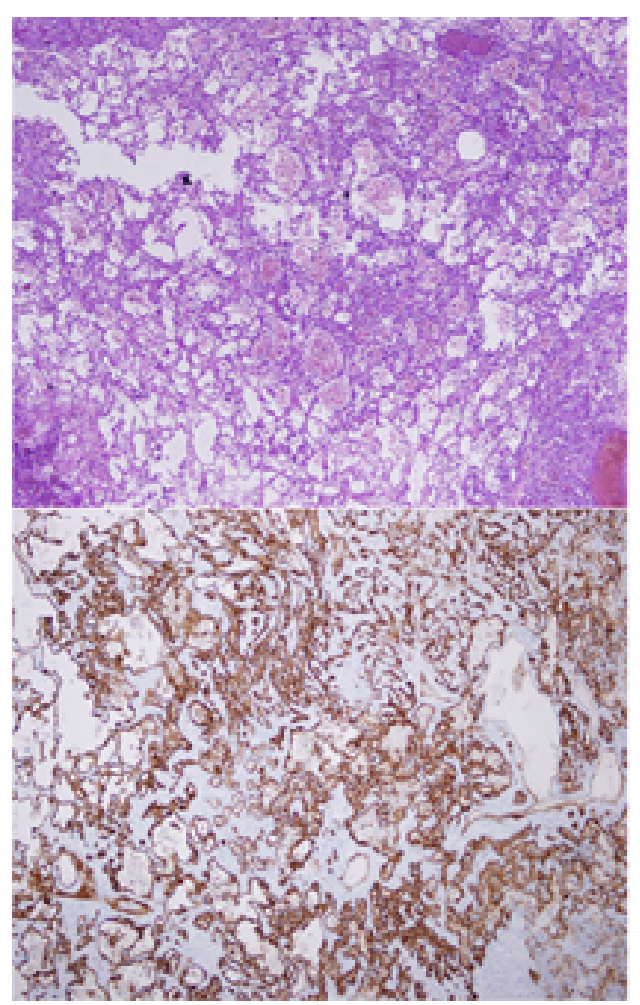

Figure 2: (a) Numerous thin walled vascular spaces, lined by a single layer of flattened endothelial cells ( $\mathrm{H}$ and $\mathrm{E})$. (b) The endothelial cells show diffuse positivity for CD34 stain.

The vascular lining was positive for CD31 and CD34. No further treatment was given to the patient. On follow-up, there was no ascites and the CA125 serum levels returned to normal.

Most of the cases are asymptomatic and present as incidental findings at operation or autopsy. In few cases, patients would present with abdominal distension due to mass effect or acute abdominal pain due to torsion [1-4]. They can also present with pleural effusion or ascites (pseudo-Meigs' syndrome) [10] thrompocytopenia (KasabachMerritt syndrome), or elevated serum CA125 mimicking ovarian epithelial carcinomas as in our case $[2,11]$. They can be part of generalized hemangiomatosis or abdomino-pelvic hemangiomatosis in particular [1].

Ovarian hemangioma can also co-exist with other ovarian pathologies such as papillary serous carcinoma and mucinous cystadenoma, as well as non-ovarian pathologies such as endometrial hyperplasia, polyps or carcinoma, and carcinomas of fallopian tubes, cervix and rectosigmoid [6,7].

Macroscopically, they are red to purple nodular masses ranging in size from few millimeters to $20 \mathrm{~cm}$. They are usually unilateral but few bilateral cases were also reported. The outer surface is smooth and glistening. The cut surface is spongy and show multiloculated cystic spaces filled with blood. Most commonly, they are located in the medulla or the hilum due to the rich vasculature $[5,8]$.

Histologically, they can be either of a cavernous, capillary, or mixed type. The cavernous type is the most common type in the ovary.
Interestingly, three cases of the newly described entity "Anastomsing hemangioma" have also been reported in the ovary [12]. ovarian hemangiomas form a reasonably circumscribed lesion distinct from the remainder of the ovary, and they are composed of dilated, bloodfilled, generally thin-walled vessels ranging from small to large size, lined by a single layer of flattened endothelial cells. The vessels may be thrombosed or calcified, and may show a lobular arrangement. The intervening stroma may show inflammation, hemorrhage with hemosiderin deposits, and occasionally luteinization $[2,6]$.

The pathogenesis of stromal luteinization in ovarian hemangioma is not clearly known yet. Hence, two important hypotheses have been proposed. The first hypothesis recommended that pre-existing stromal luteinization cause hyperestrogenism and stimulate blood vessel proliferation and result in the formation of ovarian hemangioma. The second hypothesis is that the presence of an expansile ovarian hemangioma induces stromal luteinization and subsequently hyperandrogenism and hyperestrogenism as a reactive phenomenon. This is consistent with the fact that luteinization of stromal cells is confined to the stroma surrounding the mass $[6,13]$.

The main pathological differential diagnoses are normal medullary vasculature, hemangioendothelioma, angiosarcoma, lymphangioma, and monodermal teratoma with prominent vascular component [2-5].

The distinction between normally proliferating closely packed ovarian medullary blood vessels and a small hemangioma is extremely challenging especially in postmenopausal women. However, these vascular changes are often slight but more diffuse than hemangiomas and do not form a distinct mass. Additionally, the vessels will be admixed with nerve fibers and lymphatic vessels. $[4,14]$

There are only three reported cases of primary ovarian hemangioendotheliomas have been with different subtypes (kaposiform, infantile and epithelioid subtypes). They are composed of tightly packed, dilated capillary blood vessels, lined spindle, plump or epithelioid cells depending on the tumor subtypes. Slight increased cellularity and slight atypia can also be seen in addition to few typical mitotic figures. These features are missing in hemangiomas [4].

Angiosarcomas can be primary ovarian tumors or associated with ovarian cystic teratoma. They are usually unilateral, cystic and friable with hemorrhage and necrosis. Histologically, they show marked cytologic atypia and pleomorphism, papillary endothelial tufting, necrosis, hemorrhage, and increased mitotic activity. Hemangiomas do not have these nuclear features. Therefore their absence is important for the distinction of these two entities $[1-4,14]$.

Lymphangiomas are also very rare tumors in the ovary and they are composed of thin-walled vascular spaces lined by flat endothelial cells and contain pale eosinophilic homogeneous material within the vascular channels, which is absent in hemangiomas. The endothelial cells are often positive for CD31 and D2-40, which is more specific to lymphatic channels $[1,3,10]$.

Ovarian teratomas can host both benign and malignant vascular tumors as well as reactive vascular proliferations mimicking hemangiomas. In the later, there will be small to large vascular structures lined by oval to spindle mildly atypical endothelial cells. Teratomas with hemangiomatous component are usually distinguished from a pure hemangioma by the presence of skin adnexa or other ectodermal, endodermal, or mesodermal tissue components. Hence, adequate sampling is critical in such cases [2-5]. 
Citation: Al-Shaikh SAH (2016) Ovarian Hemangioma Presenting with Ascites and Elevated CA125. J Cytol Histol 7: 409. doi: 10.4172/2157-7099.1000409

Page 3 of 3

\section{Conclusion}

Hemangiomas of the ovary are very rare neoplasms with a broad age range. These neoplasms should be considered in the differential diagnosis of any hemorrhagic ovarian lesion grossly and any ovarian lesion presenting clinically with ascites and elevated serum CA125 as in our case.

\section{References}

1. Talerman A (2011) Nonspecific tumors of the ovary, including mesenchymal tumors. In Kurman RJ editors. Blaustein's Pathology of the female genital tract. (6thedn) New York: Springer Verlag pp: 915-917.

2. Mitra B, Sengupta S, Rai A, Mehta J, Quader AR, et al. (2013) Ovarian haemangioma: a rare case report. Int J Surg Case Rep 4: 981-4.

3. Bolat F, Erkanli S, Kocer NE (2010) Ovarian hemangioma: Report of two cases and review of the literature. Turk Patoloji Derg 26: 264-6.

4. Kefili M, Karagoz F, Malpica A (2014) Co-Existence of a Large Ovarian Hemangioma and Microscopic Dysgerminoma in a 10-Year Old Child. Turk Patoloji Derg 30: 210-214.

5. Bodal VK, Kaur S, Kaur M, Jassal V, Singh Y, et al. (2015) Hemangioma ovary - A rare case report. J Punjab Acad Forensic Med Toxicol 15.

6. Shirazi B, Anbardar MH, Azarpira N, Robati M (2015) An incidental ovarian mass: A case of ovarian hemangioma with prominent stromal luteinization. Med J DY Patil Univ 8.
7. Akbulut M, Bir F, Colakoğlu N, Soysal ME, Duzcan SE (2008) Ovarian hemangioma occurring synchronously with serous papillary carcinoma of the ovary and benign endometrial polyp. Ann Saudi Med 28: 128-31.

8. Andola US, Andola SK (2011) Vascular tumours of the female genital tract: A clinicopathologic study of 11 cases. J Clin Diagn Res 5: 1241-6.

9. Goldblum JR, Folpe AL, Weiss SW (2014) Enzinger and Weiss's Soft Tissue Tumors. (6thedn) Philadelphia: Elsevier 639-80.

10. Kaneta Y, Nishino R, Asaoka K, Toyoshima K, Ito K, et al. (2003) Ovarian hemangioma presenting as pseudo- Meigs' syndrome with elevated CA125. J Obstet Gynaecol Res 29: 132-135.

11. Erdemoglu E, Kamaci M, Ozen S, Sahin G (2006) Ovarian hemangioma with elevated CA125 and ascites mimicking ovarian cancer. Eur J Gynaecol Oncol 27: 195-6.

12. Kryvenko O, Gupta N, Meier F, Lee M, Epstein J (2011) Anastomosing hemangioma of the genitourinary system: eight cases in the kidney and ovary with immunohistochemical and ultrastructural analysis. Am J Clin Pathol 136: 450-457.

13. Huang R, Covinsky M, Zhang S (2013) Bilateral Ovarian Capillary Hemangioma with Stromal Luteinization and Hyperandrogenism. Ann Clin Lab Sci 43: 457-9.

14. Percinel S, Savas B, Yilmaz G, Ceyhan K, Sonmezer M (2008) Ovarian Cavernous Hemangioma: A Case Report and Review of the Literature with Reference to Controversial Pathological Diagnoses. Gazi Med J 19: 89-92. 